\title{
Plasma and Urinary II-Hydroxycorticosteroids in Differential Diagnosis of Cushing's Syndrome
}

\author{
D. MATTINGLY, CHRISTINE TYLER
}

British Medical fournal, 1972, 3, 17-21

\section{Summary}

Morning plasma 11-hydroxycorticoids, urinary 11hydroxycorticoids, and urinary 17-oxogenic steroids were measured before and during a dexamethasone suppression test. This consisted in the administration by mouth of $2 \mathrm{mg}$ of dexamethasone daily for 48 hours, followed by $8 \mathrm{mg}$ daily for 48 hours. In addition midnight plasma 11-hydroxycorticoids were measured before the start of the test. The subjects investigated were 21 patients with Cushing's syndrome, 27 obese female patients, 10 female patients with the Stein-Leventhal syndrome, and 8 female patients with idiopathic hirsutism.

The results showed that the clearest distinction between the groups was made by measurement of the basal urinary 11-hydroxycorticoid excretion, where, in the group of patients with Cushing's syndrome, all the levels were well above the upper limit of normal. In addition raised midnight plasma 11-hydroxycorticoid levels were of great diagnostic value. By using these results together with those of the dexamethasone suppression tests it was possible to make a firm preoperative diagnosis of pituitary-dependent Cushing's syndrome in $90 \%$ of patients in this series.

\section{Introduction}

We have already shown the value of estimations of free urinary 11-hydroxycorticosteroids (11-OHCS) as a simple screening test for Cushing's syndrome (Mattingly and Tyler, 1967). The present paper describes an extension of this work in which plasma and urinary 11-OHCS estimations were used both at rest and during a dexamethasone suppression test.

Although suppression tests are widely used in investigating patients with suspected Cushing's syndrome, the dose and nature of the steroid used varies from test to test, and the methods of measuring the adrenal response are also different (Cope, 1956; Liddle, 1960; Slater et al., 1962; Nugent, Nichols, and Tyler, 1965; McHardy-Young et al., 1967; Hartog et al., 1968). In this investigation we followed the procedure first described by Liddle (1960) and measured the adrenal response after dexamethasone given by mouth for a period of 48 hours at each of two dose levels. In addition to plasma and urinary 11-OHCS levels we also measured urinary 17-oxogenic steroid (17-OGS) excretion as an index of adrenal suppression, in contrast to Liddle who measured only the urinary 17-hydroxycorticosteroids. Twenty-one patients with Cushing's syndrome were investigated in this way and the results are compared with those found in obese and hirsute patients.

\section{Patients and Methods}

The patients were divided into three groups:

(1) A group of 21 patients with Cushing's syndrome. The series consisted of 17 female and 2 male patients with bilateral

Postgraduate Medical Institute, University of Exeter adrenal hyperplasia, one female patient with an adrenal adenoma, and one male with the ectopic ACTH syndrome due to an oatcell carcinoma of the bronchus. The diagnosis was confirmed by inspection of the adrenal glands at operation or necropsy. In 18 of the 19 cases of adrenal hyperplasia the adrenal glands were enlarged, and in all 19 patients they showed the histological changes of cortical hyperplasia described by Symington (1969).

(2) A group of 27 female patients who were obviously obese but had no other manifestation of Cushing's syndrome.

(3) A group of 18 female patients who had developed hirsutism after puberty. Ten of these were cases of the Stein-Leventhal syndrome. The aetiology in the remaining eight cases was obscure, and they are referred to as cases of idiopathic hirsutism. Cases of congenital adrenal hyperplasia were specifically excluded from the investigation.

All the subjects were inpatients throughout the investigation and followed a normal ward routine. At least 24 hours were allowed to elapse between admission to hospital and the start of the investigations. Care was taken to ensure that the patients were not subjected to any stressful procedure during the tests.

Basal Levels.-Blood was taken for plasma 11-OHCS estimations between 9 and 10 a.m. on two consecutive days, and a midnight sample was taken on one of these days. Particular care was taken to ensure that the patients were not forewarned of this latter test and that they were asleep at the time. During this time two 24-hour urine collections were made for steroid estimations. The mean values of the morning plasma 11-OHCS and urinary 11-OHCS were used.

Dexamethasone Suppression Test.-Dexamethasone was administered by mouth at six-hourly intervals at two dose levels: Initially a dose of $2 \mathrm{mg}$ daily was given for 48 hours followed by a daily dose of $8 \mathrm{mg}$ for a further 48 hours. For administrative convenience this test started at 12 noon in order to ensure that the morning blood samples could be taken before changing the dose. Urine was collected during the second 24-hour period on each dose level for 11-OHCS and 17-OGS estimations. In an investigation of this sort it is inevitable that for one reason or another an occasional specimen is lost, and this accounts for the fact that the data reported do not always coincide with the numbers of patients in each group. The entire procedure took eight days to complete and is illustrated in Fig. 1.

\section{ESTIMATION OF PLASMA 11-OHCS}

The fluorimetric technique described by Mattingly (1962) was used with 2-ml samples of plasma. The Medical Research

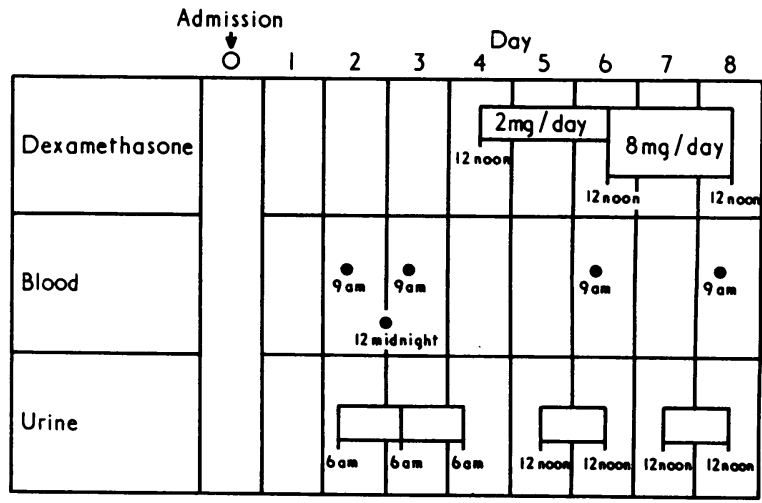

FIG. 1-Procedure for investigating patients. 
Council have published a recommended method for the estimation of plasma fluorogenic corticosteroids, which is based on a similar procedure (James, Mattingly, and Daly, 1971). In our hands the two techniques give identical results. Although dexamethasone is an 11-OHCS it does not fluoresce in the acid reagent used, so that endogenous 11-OHCS can be followed during its administration.

\section{ESTIMATION OF URINARY 11-OHCS}

The fluorimetric method developed by Mattingly et al. (1964) was used with 2-ml samples of urine. In this technique, too, the fluorescence is measured against a cortisol standard although it is well recognized that this steroid accounts for only a variable proportion of the activity estimated in urine (Espiner, 1965).

All urines were collected into acid-washed or Decon-washed bottles and aliquots were deep-frozen within three hours of completion of the collection if not assayed immediately (Mattingly and Tyler, 1967).

\section{ESTIMATION OF 17-OGS}

These were measured in the routine biochemistry laboratory by the method of Gibson and Norymberski (1954) or of Appleby et al. (1955).

\section{Results}

\section{PLASMa 11-OHCS}

\section{Midnight Levels}

In our experience, based on 28 unstressed sleeping subjects, the mean normal level of free plasma 11-OHCS at midnight is $3.3 \mu \mathrm{g} / 100 \mathrm{ml}$ and does not exceed $8 \mu \mathrm{g} / 100 \mathrm{ml}$. We have therefore assumed that higher levels indicate a disturbance of circadian rhythm.

Nineteen of the 21 patients with Cushing's syndrome had levels above the upper limit of normal. Of the two patients with normal levels one had a level of $23.3 \mu \mathrm{g} / 100 \mathrm{ml}$ at midnight on a subsequent occasion. By contrast, raised midnight levels were seen in only three of the 21 obese patients and in only three of the 12 hirsute females in whom this estimation was carried out (Fig. 2).

\section{Morning Levels}

Our normal range for plasma 11-OHCS measured in 100 patients between 9 a.m. and 10 a.m. is 6 to $24 \mu \mathrm{g} / 100 \mathrm{ml}$, with a

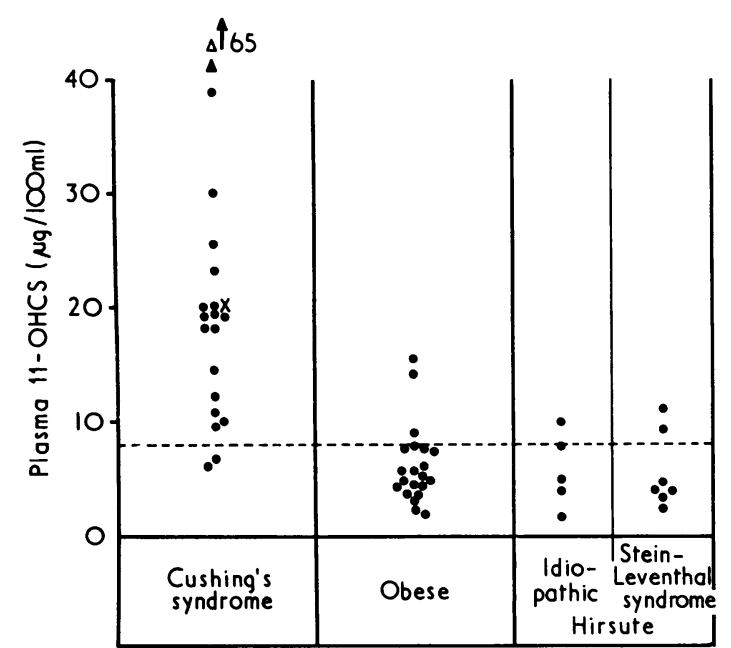
FIG. 3-Midnight plasma 11-OHCS levels in patients with Cushing's
syndrome, obesity, and hirsutism. $=$ Female. $A=M a l e . X=$ Female with adenoma. $\triangle=$ Male with ectopic ACTH syndrome. Horizontal dashed line represents upper limit of normal range at midnight. mean level of $14 \cdot 7 \mu \mathrm{g} / 100 \mathrm{ml}$ (Mattingly, 1963). A level of less than $6 \mu \mathrm{g} / 100 \mathrm{ml}$ at this time has been taken as evidence of normal pituitary-adrenal suppression, since in 14 normal subjects the morning plasma 11-OHCS level was reduced to less than this value after 48 hours on $2 \mathrm{mg}$ of dexamethasone a day (Mattingly, 1968).

Morning plasma 11-OHCS levels were raised in 15 of the 21 patients with Cushing's syndrome. Only one of the 27 obese patients, however, and none of the 18 hirsute patients had levels outside the normal range (Fig. 3 ).

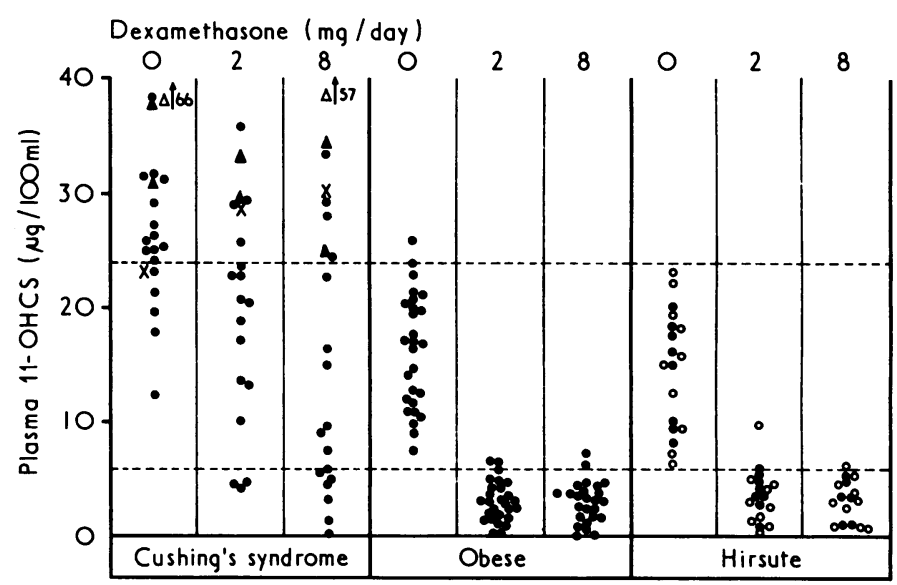

FIG. 3-Plasma 11-OHCS levels in blood taken between 9 a.m. and 10 a.m. from patients with Cushing's syndrome, obesity, and hirsutism. $=\mathrm{Fe}$ male. $\Delta=$ Male. $\mathrm{X}=$ Female with adenoma. $\Delta=$ Male with ectopic ACTH syndrome. In hirsute group $O=$ Idiopathic hirsutism. $\mathrm{O}=$ SteinLeventhal syndrome. Horizontal dashed lines represent limits of normal range.

Most of the patients with Cushing's syndrome showed some resistance to suppression of the pituitary-adrenal axis by the dexamethasone. Of the 19 patients with adrenal hyperplasia 16 failed to suppress to less than $6 \mu \mathrm{g} / 100 \mathrm{ml}$ on $2 \mathrm{mg}$ of dexamethasone daily. When the larger dose of $8 \mathrm{mg}$ of dexamethasone daily was given the plasma 11-OHCS levels fell to less than half the basal levels in 10 of the 19 patients; no significant fall was seen in the patients with the adrenal adenoma or ectopic ACTH syndrome on either dosage.

By contrast most of the obese patients suppressed to below $6 \mathrm{\mu g} / 100 \mathrm{ml}$ on the $2-\mathrm{mg}$ daily dose of dexamethasone. The level in the two obese patients who did not suppress completely on this dose was only $6.8 \mu \mathrm{g} / 100 \mathrm{ml}$ in each case. All the hirsute patients had levels below $6 \mu \mathrm{g} / 100 \mathrm{ml}$ on $2 \mathrm{mg}$ of dexamethasone daily except one who had a level of $10.0 \mu \mathrm{g} / 100 \mathrm{ml}$. This patient suppressed to $2 \cdot 8 \mu \mathrm{g} / 100 \mathrm{ml}$ when on the larger dose of dexamethasone.

\section{URINARY 11-OHCS}

Our range of urinary 11-OHCS found in normal subjects is $78-311 \mu \mathrm{g} / 24 \mathrm{hr}$ for women and 108-396 $\mu \mathrm{g} / 24 \mathrm{hr}$ for men (Mattingly and Tyler, 1967). Since most of the patients in this study were women we took levels of less than $80 \mu \mathrm{g} / 24 \mathrm{hr}$ during the administration of dexamethasone as an indication of normal pituitary-adrenal suppression.

All the 21 basal samples from the patients with Cushing's syndrome were above the upper limit of our normal range, the lowest value being $390 \mu \mathrm{g} / 24 \mathrm{hr}$ in a female patient. In contrast, the levels in 25 of the 26 obese patients fell within the normal range, the exception being only slightly raised at $327 \mu \mathrm{g} / 24 \mathrm{hr}$. Three of the 18 hirsute patients had basal levels which were slightly raised, the highest of which was $417 \mu \mathrm{g} / 24 \mathrm{hr}$ (Fig. 4).

Most of the patients with adrenal hyperplasia showed some resistance to suppression of their pituitary-adrenal axis by oral dexamethasone judged by the urinary steroid excretion. Only one of the 18 patients on $2 \mathrm{mg}$ of dexamethasone daily sup- 


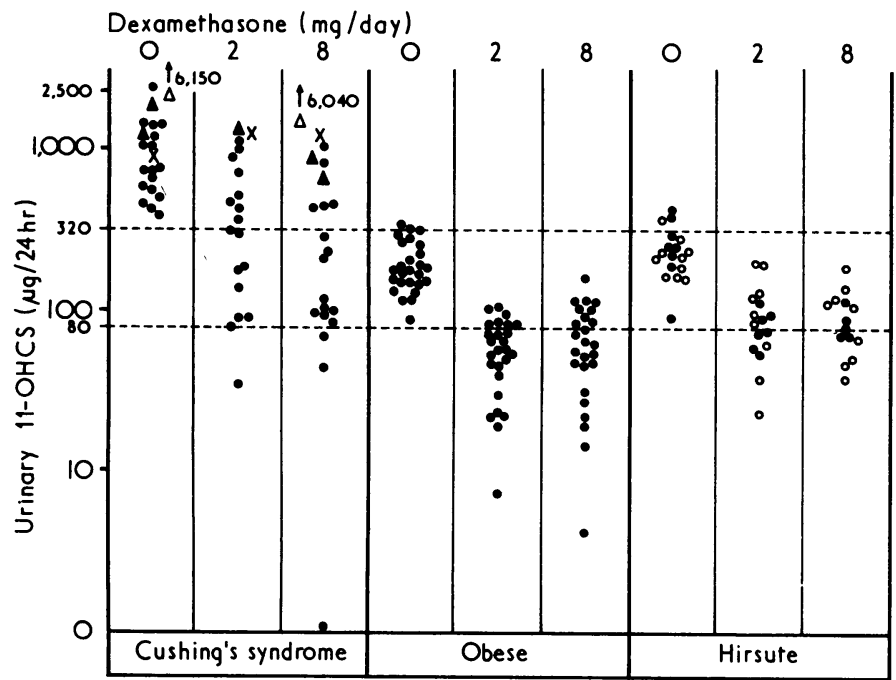

FIG. 4-Urinary 11-OHCS levels in patients with Cushing's syndrome and in obese and hirsute patients. Ordinate plotted on logarithmic scale. $=$ Female. $\Delta=$ Male. $\mathbf{X}=$ Female with adenoma. $\Delta=$ Male with ectopic ACTH syndrome. In hirsute group $=$ Idiopathic hirsutism. $\mathrm{O}=$ SteinLeventhal syndrome. Horizontal dashed lines represent limits of normal range.

pressed normally to less than $80 \mathrm{\mu g} / 24 \mathrm{hr}$. On the larger dose of $8 \mathrm{mg}$ daily, however, the urinary 11-OHCS levels fell to less than half the basal levels in 17 of the 19 patients; no significant fall was seen in the patients with the adrenal adenoma and ectopic ACTH syndrome on either dosage.

In contrast 19 of the 26 obese patients had levels below $80 \mu \mathrm{g} / 24 \mathrm{hr}$ when on $2 \mathrm{mg}$ of dexamethasone daily. More than half of the hirsute patients showed an abnormal response to dexamethasone. In nine of the 16 patients on $2 \mathrm{mg}$ daily, levels of above $80 \mu \mathrm{g} / 24 \mathrm{hr}$ were found.

\section{URINARY 17-OGS}

The normal range that we have adopted for adult women is $5-18 \mathrm{mg} / 24 \mathrm{hr}$ (Brooks et al., 1963). A level of less than $5 \mathrm{mg} / 24$ $\mathrm{hr}$ during the administration of dexamethasone was taken as evidence of normal pituitary-adrenal suppression.

In the patients with Cushing's syndrome under basal conditions 13 levels were above the upper limit of normal but seven levels fell within the normal range. On the other hand none of the estimations on the obese patients and only two on the 18 hirsute patients were raised (Fig. 5).

In the suppression tests, 13 of the 19 patients with adrenal hyperplasia on $2 \mathrm{mg}$ of dexamethasone daily failed to suppress

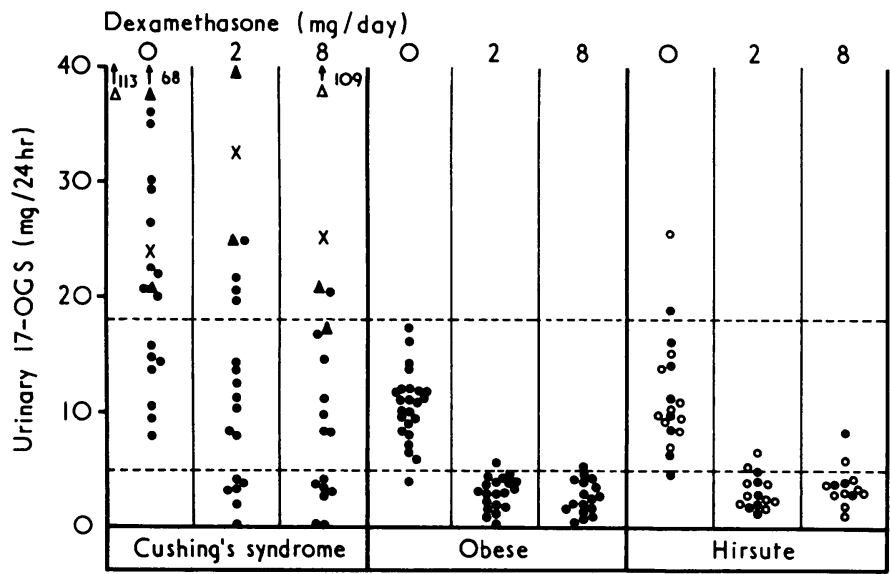

FIG. 5-Urinary 17-OGS steroid levels in patients with Cushing's syndrome and in obese and hirsute patients. $=$ Female. $\Delta=$ Male. $\mathbf{X}=$ Female with adenoma. $\triangle=$ Male with ectopic ACTH syndrome. In hirsute group 0 Idiopathic hirsutism. $O=$ Stein-Leventhal syndrome. Horizontal dashed lines represent limits of normal range. normally. On the larger dose of $8 \mathrm{mg}$ daily the urinary 17-OGS fell to less than $50 \%$ in 10 of the 16 patients tested; no significant fall was seen in the patients with the adrenal adenoma and the ectopic ACTH syndrome on either dosage. Nineteen out of 20 obese patients on $2 \mathrm{mg}$ of dexamethasone daily, however, had levels below $5 \mathrm{mg} / 24 \mathrm{hr}$. Similarly, in the hirsute group 13 of the 15 patients suppressed normally.

In summary, with regard to the suppression tests five of the 19 patients with adrenal hyperplasia showed normal suppression by one or other test on the $2-\mathrm{mg}$ dose of dexamethasone, but in only one of these six was adrenal function normally suppressed according to all three tests; all of these six patients had both raised midnight plasma $11-\mathrm{OHCS}$ and raised basal urinary 11-OHCS levels.

\section{Discussion}

It is now well recognized that adrenal overactivity may be present in patients with few signs and symptoms suggestive of classical Cushing's syndrome, and there is no single biochemical investigation in routine use which can be relied on to confirm the diagnosis in every case (Brooks et al., 1963; Cope, 1966; Ross, Marshall-Jones, and Friedman, 1966). Although measurement of the cortisol secretion rate by isotope dilution provides the most accurate estimate of adrenal activity (Cope and Black, 1958), this technique is too specialized for routine clinical use. In addition single estimations may be misleading since in some patients with adrenal hyperplasia there are wide fluctuations in adrenal activity from one day to the next. Unfortunately the estimation of urinary 17-OGS does not provide a reliable guide to the cortisol secretion rate, and it is not uncommon to find normal levels in Cushing's syndrome (Cope and Pearson, 1965; Ross, Marshall-Jones, and Friedman, 1966).

In a previous paper we discussed the difficulties in making a diagnosis of Cushing's syndrome, especially in patients who are not grossly diseased, and drew attention to the value of urinary 11-OHCS estimations as a screening test for adrenocortical hyperfunction (Mattingly and Tyler, 1967). Since, however, treatment of Cushing's syndrome at present involves pituitary irradiation or major surgery on the adrenal or pituitary glands, we have been reluctant to advise such procedures on the basis of the urinary 11-OHCS results alone, even when these are persistently raised. For this reason it has been our policy to admit patients with raised levels for further investigations.

Previous work has shown that the morning plasma corticosteroid levels in cases of Cushing's syndrome frequently overlap with the normal range at this time of day, but midnight levels taken during sleep are of much greater diagnostic value, since the normal circadian rhythm of adrenocortical activity is often absent or severely reduced in this disease (Doe, Vennes, and Flink, 1960; Ekman et al., 1961; Mattingly, 1963; Summers et al., 1964; Cope, 1966). Two of the patients with Cushing's syndrome in the present series, however, had normal midnight levels on one occasion, although one of these had a raised level subsequently. The other was not retested. Ross et al. (1966) also reported on a patient with Cushing's syndrome who had a normal midnight level on one occasion although it was raised on another.

A few of the present obese and hirsute patients had levels which were above our upper limit of normal for midnight, but the levels exceeded $11 \mu \mathrm{g} / 100 \mathrm{ml}$ in only two of the obese patients. Raised midnight levels have been reported in stressed patients, and in particular in patients suffering from depression (Fawcett and Bunney, 1967; Butler and Besser, 1968; Carroll, Martin, and Davies, 1968). It is possible that the occasional raised midnight levels found in the obese and hirsute patients was the result of the mental stress of admission to hospital. Nevertheless, the possibility of early Cushing's syndrome cannot be completely excluded in these cases, even when all the other tests are normal. Eight years ago we investigated a patient not included in this series in whom the only abnormality found 
was a raised midnight plasma 11-OHCS level of $11.6 \mu \mathrm{g} / 100 \mathrm{ml}$. Recently she presented elsewhere with more definite features of this disorder and failed to suppress on dexamethasone. At operation she was found to have bilateral adrenal hyperplasia.

It has been shown that adrenocortical activity is rapidly suppressed in normal subjects by the administration of corticosteroids by mouth, but varying degrees of resistance to suppression have been shown in patients with Cushing's syndrome (Liddle, 1960; Slater et al., 1962; Hartog et al., 1968; Mattingly, 1968). A test with a single dose of dexamethasone given at midnight has been described by several workers, the adrenal response being measured by the fall in plasma 11-OHCS level the following morning (McHardy-Young et al., 1967; Seidensticker et al., 1967). Connolly et al. (1968), however, studied 108 hospital patients of whom one-third failed to suppress normally using this single-dose test. They came to the conclusion that the inability to obtain suppression in these patients could be due to the "non-specific stress" of being in hospital rather than to a disturbance of circadian rhythm.

In view of these conflicting results we have preferred to use the more prolonged dexamethasone suppression test described by Liddle (1960), using both plasma and urinary steroid levels as a measure of the adrenal response. Liddle's results suggested that is was possible to separate the patients with Cushing's syndrome from those without by their failure to suppress normally on $2 \mathrm{mg}$ of dexamethasone daily for 48 hours. He used the Porter-Silber technique for the estimation of urinary 17-OHCS, which is not widely used in the U.K., and took $4 \mathrm{mg} / 24 \mathrm{hr}$ as the upper limit of normal excretion on this dose of steroid. Inspection of his data, however, shows that one patient who was thought to have bilateral adrenal hyperplasia suppressed to $4 \mathrm{mg} / 24 \mathrm{hr}$ and two others suppressed to $5 \mathrm{mg} / 24 \mathrm{hr}$, so that even in his series there were borderline cases. In the present patients with adrenal hyperplasia the results of the dexamethasone suppression tests are not as clear cut as those of Liddle. Although most of them failed to suppress normally on $2 \mathrm{mg}$ of dexamethasone daily for $\mathbf{4 8}$ hours there was some overlap with the obese and hirsute groups. The least overlap was seen in the plasma 11-OHCS results, where three patients with adrenal hyperplasia apparently suppressed normally while four obese subjects and one hirsute patient had levels which were just above the arbitrary limit.

Only one patient with adrenal hyperplasia suppressed normally on this steroid dosage according to the urinary 11-OHCS level, but this test was less precise than the plasma tests in differentiating the three groups since seven of the obese and nine of the hirsute patients also failed to suppress normally. The same overlap occurs with the urinary 17-OHCS results.

There is no doubt, however, that the three patients in the adrenal hyperplasia group whose plasma 11-OHCS levels were suppressed normally by $2 \mathrm{mg}$ of dexamethasone daily did indeed have adrenocortical hyperfunction. One patient had signs and symptoms of this disease for 10 years, which were relieved by bilateral adrenalectomy; her adrenal glands weighed 6.8 and $7.5 \mathrm{~g}$ free of fat, and she developed severe pigmentation and radiological evidence of a pituitary tumour two years after adrenalectomy. A second patient also underwent adrenalectomy with relief of symptoms, and one of her adrenal glands weighed $15.0 \mathrm{~g}$. The third patient, aged 46 , presented with obesity, a blood pressure of $260 / 140$, and pronounced hirsutism. Although the adrenal glands were not weighed they showed conspicuous hyperplasia of the zona reticularis, and columns of compact cells occupied the lower half of the zone fasciculata. After adrenalectomy her blood pressure fell to $150 / 100 \mathrm{~mm} \mathrm{Hg}$ on maintenance steroid therapy, her hirsutism regressed, and she lost nearly 2 stone $(13 \mathrm{~kg}$ ) in weight. The clinical diagnosis was never in doubt in these three patients and was supported by raised urinary 11-OHCS and midnight plasma 11-OHCS levels.

We excluded the diagnosis of adrenal hyperplasia in the patients in the obese and hirsute groups who failed to suppress normally, mainly on the grounds that they had normal midnight plasma 11-OHCS and normal basal urinary 11-OHCS and
17-OGS excretion. Final proof, however, is lacking since their adrenal glands were not removed, and only time will tell if we were correct in this assumption.

Liddle (1960) suggested that it was possible to separate patients with bilateral adrenal hyperplasia due to inappropriate pituitary ACTH secretion from those with autonomously functioning adrenal tissue by giving $8 \mathrm{mg}$ of dexamethasone daily for two to three days. He found that all his 16 patients with bilateral adrenal hyperplasia had a decrease in urinary 17OHCS to less than half the basal values on the second and third days of dexamethasone administration. By contrast there was no significant change in seven patients with adrenocortical tumours. In our series the urinary 11-OHCS fell to less than half the basal levels in 17 of the 19 patients with adrenal hyperplasia, but a reduction to $50 \%$ of the basal levels of urinary 17-OGS was seen in only 10 of the 15 patients tested. As in Liddle's series no significant suppression of urinary steroid excretion was seen in the one patient with an adrenocortical tumour.

Morning plasma 11-OHCS levels after 48 hours on $8 \mathrm{mg}$ of dexamethasone a day were also useful in distinguishing patients with pituitary-dependent Cushing's syndrome. A fall of more than $9 \mu \mathrm{g} / 100 \mathrm{ml}$ from the basal level was found in 15 of the 17 patients with adrenal hyperplasia whose urinary 11-OHCS levels were suppressed according to the criteria discussed above. In only two patients with adrenal hyperplasia was inadequate suppression of both plasma and urinary steroids seen at this dose level. No suppression occurred in the patient with the adrenal adenoma or in the one patient with the ectopic ACTH syndrome.

\section{Conclusions}

In our experience the most useful criteria for confirming the diagnosis of Cushing's syndrome are a raised midnight plasma 11OHCS level taken during sleep, raised basal urinary 11-OHCS levels estimated on at least two occasions, and failure of the morning plasma 11-OHCS level to suppress below $6 \mu \mathrm{g} / 100 \mathrm{ml}$ in response to $2 \mathrm{mg}$ of dexamethasone daily for 48 hours. When suppression does not occur on this dose of dexamethasone it is necessary to give a much larger dose in order to try to determine the underlying aetiology. By using plasma and urinary 11OHCS estimations alone it was possible to make a firm preoperative diagnosis of pituitary-dependent Cushing's syndrome in $90 \%$ of these patients with this disorder. Where clear-cut suppression on dexamethasone does not occur the possibility of an adrenal tumour or ectopic ACTH syndrome must be considered.

We should like to thank Mr. J. Barraclough for the 17-OGS estimations, and Mrs. Elaine Bilton and Mr. H. Martin for excellent technical help. We are also indebted to the Medical Research Council, the Northcott Devon Medical Foundation, and the South-western Regional Hospital Board for financial support.

\section{References}

Appleby, J. I., Gibson, G., Norymberski, J. K., and Stubbs, R. D. (1955). Biochemical fournal, 60,453

Brooks, R. V., Dupré, J., Gogate, A. N., Mills, I. H., and Prunty, F. T. G. (1963). Fournal of Clinical Endocrinology and Metabolism, 23, 725.

Butler, P. W. P., and Besser, G. M. (1968). Lancet, 1, 1234.

Carroll, B. J., Martin, F. I. R., and Davies, B. (1968). British Medical

Fournal, 3, 285.
Connolly, C. K., Gore, M. B. R., Stanley, N., and Wills, M. R. (1968). British Medical fournal, 2, 665.

Cope, C. L. (1956). British Medical fournal, 2, 193.

Cope, C. L. (1966). British Medical Ұournal, 2, 847.

Cope, C. L., and Black, E. (1958). British Medical fournal, 1, 1020

Cope, C. L., and Pearson, J. (1965). Fournal of Clinical Pathology, 18, 82. Doe, R. P., Vennes, J. A., and Flink, E. B. (1960). Fournal of Clinical Endocrinology and Metabolism, 20, 253.

Ekman, H., Häkansson, B., McCarthy, J. D., Lehmann, J., and Siögren, B. (1961). Fournal of Clinical Endocrinology and Metabolism, 21, 684.

Espiner, E. A. (1965). Fournal of Endocrinology, 33, 233. Fawcett, J. A., and Bunney, W. E. (1967). Archives of General Psychiatry,
16, 517. 
Gibson, G., and Norymberski, J. K. (1954). Annals of the Rheumatic Diseases, 13, 59 . Hartog, M., Joplin, G. F., Fotherby, K., Mattingly, D., and Fraser, T. R.
(1968). In Investigation of Hypothalamic-Pituitary-Adrenal Function ed. V. H. T. James and J. Landon, p. 271. London, Cambridge University Press.

James, V. H. T., Mattingly, D., and Daly, J. R. (1971). British Medical fournal, 2,310 .

Liddle, G. W. (1960). Fournal of Clinical Endocrinology and Metabolism, 20,1539 .

McHardy-Young, S., Harris, P. W. R., Lessof, M. H., and Lyne, C. (1967). British Medical fournal, 2,740

Mattingly, D. (1962). Fournal of Clinical Pathology, 15, 374.

Mattingly, D. (1963). Proceedings of the Royal Society of Medicine, 56, 717.

Mattingly, D. (1968). In Recent Advances in Medicine, ed. D. N. Baron, N. Compton, and A. M. Dawson, p. 157. London, Churchill.
Mattingly, D., Dennis, P. M., Pearson, J., and Cope, C. L. (1964). Lancet 2, 1046 .

Mattingly, D., and Tyler, C. M. (1967). British Medical fournal, 4, 394.

Nugent, C. A., Nichols, T., and Tyler, F. H. (1965). Archives of Internal Medicine, 116, 172.

Ross, E. J., Marshall-Jones, P., and Friedman, M. (1966). Quarterly fournal of Medicine, 35, 149

Seidensticker, J. F., Folk, R. L., Wieland, R. G., and Hamwi, G. J. (1967). Fournal of the American Medical Association, 202, 87

Slater, J. D. H., Hartog, M., Fraser, R., and Rantzen, B. (1962). British Medical fournal, 1, 1584

Summers, V. K., Sheehan, H. L., Hipkin, L. J., and Davis, J. C. (1964). Lancet, 2, 1079.

Symington, T. (1969). Functional Pathology of the Human Adrenal Gland, p. 109. Edinburgh, Livingstone.

\title{
In-vivo Cytogenetic Effects of Perphenazine and Chlorpromazine: A Negative Study
}

\author{
MAIMON M. COHEN, ERNEST LIEBER, HOWARD N. SCHWARTZ
}

British Medical fournal, 1972, 3, 21-23

\section{Summary}

No evidence was found that either perphenazine or chlorpromazine induced chromosomal damage in patients given the drugs. These results were reached independently at two separate laboratories; earlier reports of possible adverse cytogenetic effects of these drugs can probably be discounted.

\section{Introduction}

During the past few years the cytogenetic effects of an increasing number of psychotropic agents have been investigated (Cohen et al., 1967; Cohen et al., 1969; Nielsen et al., 1969; Schmid and Staiger, 1969; Staiger, 1969; Stenchever and Frankel, 1969). Simple explanations for the apparent conflicting observations obtained with some drugs are exceedingly difficult to propose, but such factors as observer differences and differences in tissue culture medium, culture time, and technique have been suggested. This report assesses the possible induction of in-vivo chromosomal damage by two psychotropic agents (perphenazine and chlorpromazine) which have previously been implicated as "chromosome breakers" (Cohen et al., 1967; Nielsen et al., 1969). The experiment was designed to test for differences between the procedures used in two different cytogenetic laboratories.

\section{Materials and Methods}

Nineteen drug-treated male subjects aged 23-63 years were studied. They were patients at the Neuropsychiatric Institute, Princeton, New Jersey. All had histories of chronic schizophrenic reactions of various types, and all had received daily doses of standard and investigational drugs for up to two years before the experiment began.

\footnotetext{
Department of Pediatrics, Bufialo Children's Hospital, Bufialo, New York 14222, U.S.A.

MAIMON M. COHEN, PH.D., Associate Professor of Pediatrics and Director of Cytogenetics

Beth Israel Hospital, New York, U.S.A.

ERNEST LIEBER, M.D., Chief, Medical Genetics Unit

Schering Corporation, Bloomfield, New Jersey, U.S.A.

HOWARD N. SCHWARTZ, M.D., Director, Department of Clinical Pharmacology
}

Perphenazine was given to nine patients in increasing doses over a six-week period. Daily doses were increased every two days, ranging from $8 \mathrm{mg} /$ day to a maximum of $48 \mathrm{mg} /$ day. The average total dose per patient was $1,110 \mathrm{mg}$ during the six-week period.

Chlorpromazine was given to 10 patients. The daily dose range was increased from $150 \mathrm{mg}$ to $600 \mathrm{mg} /$ day at about two-day intervals during the six-week study. Average total dose per patient was $18,565 \mathrm{mg}$.

Six normal males were selected as controls from hospital personnel with no history of previous drug ingestion who worked on the same wards as the patients.

During the course of this study none of the volunteers or patients needed radiological procedures or suffered any intercurrent illness or viral infections.

Experimental Design.-Drugs were discontinued in all cases for one month before the study began (washout, period 1). Blood samples were obtained for chromosome analysis at the beginning of the washout phase and again at its completion (baseline, period 2). Similar samples were then obtained after three (period 3) and six (period 4) weeks of daily drug ingestion. At the completion of period 4 all drugs were withheld for up to one month, and a final blood sample was obtained (period 5) before reinstitution of therapy.

Chromosome Preparations. - Blood samples were collected in heparinized syringes which were numerically coded. Three to five drops of whole blood was inoculated into each of four microculture tubes (chromosome medium 1A, GIBCO). Two tubes were sent to each of the participating cytogenetics laboratories (New York City and Buffalo) for culture and analysis. The same batch of medium was used throughout the study. Similar procedures of culture, harvesting, slide preparation, and scoring were used in both laboratories. The cultures were incubated at $37^{\circ} \mathrm{C}$ for 72 hours, the final two hours in the presence of Colcemid (demecolcine) $(0.5 \mu \mathrm{g} / \mathrm{ml})$ or Velban (vinblastine sulphate) $(0.05 \mu \mathrm{g} / \mathrm{ml})$. The cultures were harvested after a slight modification of the method of Moorhead et al. (1960). After centrifugation the supernate was discarded and the cells were resuspended in hypotonic sodium citrate $(1 \%)$ or fetal calf serum in distilled water $(1: 5)$ for $15 \mathrm{~min}$ at $37^{\circ} \mathrm{C}$. The cells were then fixed in several changes (10 min each) of the $3: 1$ methanol: glacial acetic acid fixative. Two drops of cell suspension were then placed on a chilled, prewet (either distilled water or $70 \%$ methanol) microscope slide and passed through a flame for ignition. The slides were stained in $2 \%$ acetic orcein or Giemsa and dehydrated in a graduated series of alcohol, and a coverslip was mounted with Permount. 